\title{
Fuzzy-Sliding Mode Speed Control for Two Wheels Electric Vehicle Drive
}

\author{
Abdelfatah Nasri ${ }^{\dagger}$, Abdeldjabar Hazzab*, Ismail Khalil Bousserhane*, \\ Samir Hadjeri** and Pierre Sicard ${ }^{* * *}$
}

\begin{abstract}
Electric vehicles (EV) are developing fast during this decade due to drastic issues on the protection of environment and the shortage of energy sources, so new technologies allow the development of electric vehicles (EV) by means of electric motors associated with static converters. The proposed propulsion system consists of two induction motors (IM) that ensure the drive of the two back driving wheels. The electronic differential system ensures the robust control of the vehicle behavior on the road. It also allows controlling, independently, every driving wheel to turn at different speeds in any curve. This paper presents the study of an hybrid Fuzzy-sliding mode control (SMC) strategy for the electric vehicle driving wheels, stability improvement, in which the fuzzy logic system replace the discontinuous control action of the classical SMC law. Our electric vehicle fuzzy-sliding mode control's simulated in Matlab SIMULINK environment, the results obtained present the efficiency of the proposed control with no overshoot, the rising time is perfected with good disturbances rejections comparing with the classical control law.
\end{abstract}

Keywords: electric vehicle, electronic differential, induction motor, vector control, fuzzy-sliding mode control

\section{Introduction}

Electric vehicles (EVs) are developing fast during this decade due to drastic issues on the protection of environment and the shortage of energy sources. While commercial hybrid cars have been rapidly exposed on the market, fuel-cell-powered vehicles are also announced to appear in 5-10 years. Researches on the power propulsion system of EVs have drawn significant attention in the automobile industry and among academics. EVs can be classified into various categories according to their configurations, functions or power sources. Pure EVs do not use petroleum, while hybrid cars take advantages of energy management between gas and electricity [1].

Indirectly driven EVs are powered by electric motors through transmission and differential gears, while directly driven vehicles are propelled by in-wheel or, simply, wheel motors [2]. The basic vehicle configurations of this research has two directly driven wheel motors installed and operated inside the driving wheels on a pure EV. These wheel motors can be controlled independently and have so quick and accurate response to the command that the vehicle chassis control or motion control becomes more stable and robust, compared to indirectly driven EVs. Like most

$\dagger$ Corresponding Author : Dept. of Electrical Engineering, BP.417 Bechar Univerity, Bechar (08000) ALGERIA. (nasriab1978@yahoo.fr)

* Dept. of Electrical Engineering, BP.417 Bechar Univerity, Bechar (08000) ALGERIA.

** Dept. of Electrical Engineering, University of Djillali Liabes, BP.98 Sidi Bel-Abbes (22000), ALGERIA.

*** Research group on industrial Electronics University of Quebec in Trois-Rivieres, Trois-Rivieres, CANADA.

Received : November 28, 2008; Accepted : September 5, 2009 research on the torque distribution control of wheel motor, wheel motors [3] proposed a dynamic optimal tractive force distribution control for an EV driven by four wheel motors, thereby improving vehicle handling and stability.

The researchers assumed that wheel motors were all identical with the same torque constant; neglecting motor dynamics the output torque was simply proportional to the input current with a prescribed torque constant.

In this paper, a fuzzy sliding mode decoupling controller which combines the merits of the sliding mode control and the fuzzy inference mechanism is proposed to control the electric vehicle motorization. In this scheme, a fuzzy sliding mode controllers is investigated, in which the fuzzy logic system is used to replace the discontinuous control action $(k \cdot \operatorname{sign}(s))$ of the classical SMC law to improve the propulsion system control stability.

The reminder of this paper is organized as follows: Section 2 reviews the principle components of the Electric traction chain with their equations model. Section 3 shows the indirect field-oriented control (IFOC) of induction motor. Section 4 shows the development of sliding mode controllers design for Electric vehicle motorization. Section 5 shows the proposed fuzzy-sliding mode control law model. The proposed structure of the studied propulsion system is given in the section 6 . Section 7 gives some simulation results of the different studied cases. Finally, the conclusion is drawn in section 8 .

\section{Electric traction system elements modeling}

Figure 1 represents the general diagram of an electric 
traction system using an induction motor (IM) supplied by voltage inverter $[4,8]$.

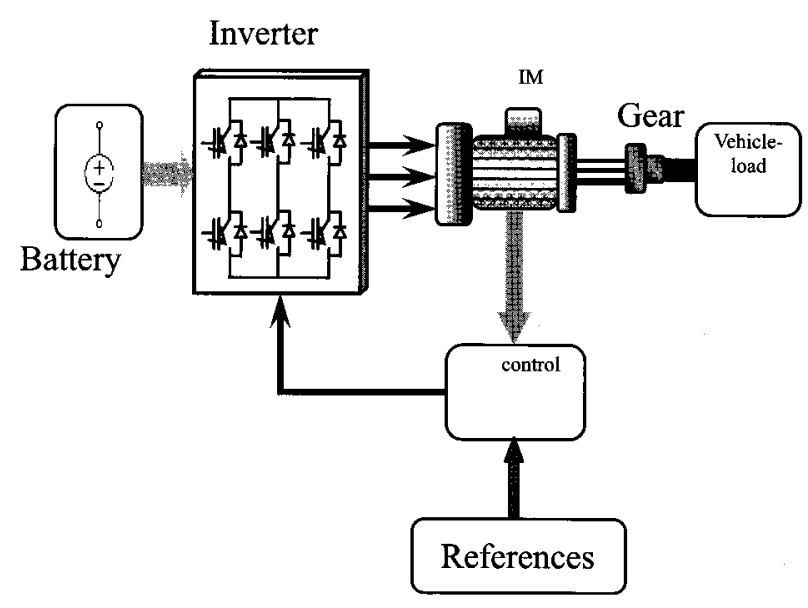

Fig. 1. Electrical traction chain

\subsection{Energy source}

The battery considered in this paper is of the LithiumIon [9], the battery current is calculated by:

$$
I_{b a t}=\frac{V_{o c}-\sqrt{V_{o c}^{2}}-4 \cdot\left(R_{\mathrm{int}}+R_{t}\right) \cdot P_{b}}{2 \cdot\left(R_{\mathrm{int}}+R_{t}\right)}
$$

where :

$P_{b}$ : Output power of battery,

$R_{\text {int }}: \quad$ Internal resistance,

$V_{o c}$ : The open circuit voltage,

$R_{t}:$ The terminal voltage of the battery.

\subsection{Static converter}

In this electric traction system, we use a three balanced phases of alternating current inverter with variable frequency from the current battery [4].

$$
\left[\begin{array}{l}
v_{a n} \\
v_{b n} \\
v_{c n}
\end{array}\right]=\frac{U_{d c}}{2}\left[\begin{array}{ccc}
2 & -1 & -1 \\
-1 & 2 & -1 \\
-1 & -1 & 2
\end{array}\right]\left[\begin{array}{l}
S_{a} \\
S_{b} \\
S_{c}
\end{array}\right]
$$

The $S_{i}$ are logical switches obtained by comparing the control inverter signals with the modulation signal.

\subsection{Traction motor}

The used motorization consist of three phase induction motor (IM) supplied by a voltage inverter controlled by Pulse Width Modulation (PWM) techniques. The dynamic model of three-phase, Y-connected induction motor can be expressed in the $d-q$ synchronously rotating frame as $[4,6$, 13]:

$$
\begin{aligned}
& \int \frac{d i_{s s}}{d t}=\frac{1}{\sigma L_{s}} \cdot\left(-\left(R_{s}+\left(\frac{L_{m}}{L_{r}}\right)^{2} R_{r}\right) i_{d s}+\sigma L_{s} \cdot \omega_{e} i_{q s} \frac{L_{m} R_{r}}{L_{r}^{2}} \cdot \varphi_{d r}+\frac{L_{m}}{L_{r}} \cdot \varphi_{q r} \omega_{r}+V_{d s}\right) \\
& \frac{d i_{i_{s}}}{d t}=\frac{1}{\sigma L_{s}}\left(-\sigma L_{s} \cdot \omega_{e} \cdot i_{d s}-\left(R_{s}+\left(\frac{L_{m}}{L_{r}}\right)^{2} R_{r}\right) i_{q s} \frac{L_{m}}{L_{r}} \cdot \varphi_{d r}, \sigma_{q}+\frac{L_{m} R_{r}}{L_{r}^{2}} \cdot \varphi_{q r}+V_{q s}\right) \\
& \left\{\frac{d \varphi_{d r}}{d t}=\frac{L_{n} R_{r}}{L_{r}} i_{d s} \frac{R_{r}}{L_{r}} \cdot \varphi_{d r}+\left(\omega_{e}-\omega_{r}\right) \varphi_{d r}\right. \\
& \frac{d \phi_{q r}}{d t}=\frac{L_{h n} R_{r}}{L_{r}} i_{q s}-\left(\omega_{e}-\omega_{r}\right) \varphi_{d r}-\frac{R_{r}}{L_{r}} \cdot \phi_{q r} \\
& \frac{d q_{q}}{d t}=\frac{3}{2} \frac{P^{2} L_{m}}{L_{r} J} \cdot i_{q_{s}}\left(\varphi_{d r}-i_{d s} \varphi_{q r}\right) \frac{f_{c}}{J} \cdot \omega_{q}-\frac{P}{J} T_{l}
\end{aligned}
$$

Where $\sigma$ is the coefficient of dispersion and is given by:

$$
\sigma=1-\frac{L_{m}^{2}}{L_{s} L_{r}}
$$$$
L_{s}, L_{r}, L_{m} \quad \text { stator, rotor and mutual inductances; }
$$$$
R_{s}, R_{r} \quad \text { stator and rotor resistances; }
$$$$
\omega_{e}, \omega_{r} \quad \text { electrical and rotor angular frequency; }
$$$$
\omega_{s l} \quad \text { Slip frequency }\left(\omega_{e}-\omega_{r}\right) \text {; }
$$$$
\tau_{r} \quad \text { Rotor time constant }\left(L_{r} / R_{r}\right) \text {; }
$$$$
P \quad \text { Pole pairs }
$$

\subsection{Mechanical part}

The developed globally traction chain model based on the data uses from the Leroy-Somer Society, [4] is shown in figure 2 :

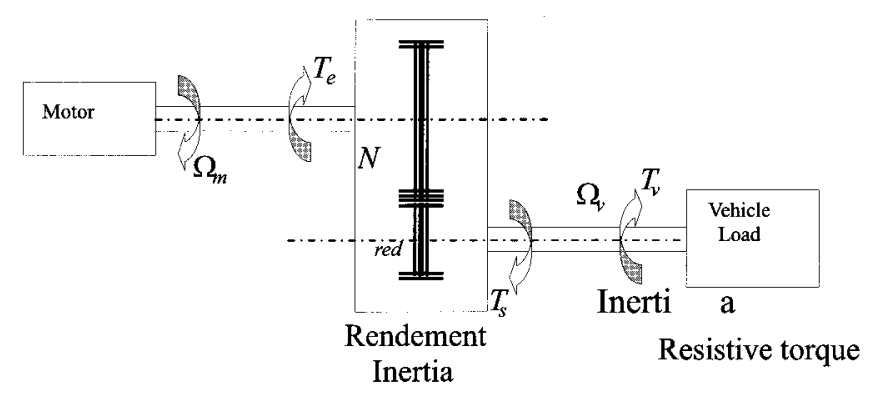

Fig. 2. Electromechanical structure

\subsubsection{The vehicle as load}

The vehicle is considered as a load is characterized by many torques which are mostly considered as resistive torques $[4,5,12,15,17,18]$. The different torques includes:

The vehicle inertia torque defined by the following relationship: 


$$
T_{i n}=J_{v} \cdot \frac{d w_{v}}{d t}
$$

The aerodynamics torque is:

$$
T_{\text {aero }}=\frac{1}{2} \rho S \cdot T_{x} \cdot R_{r}^{3} \cdot w_{r}^{2}
$$

The slope torque is :

$$
T_{\text {slope }}=M g \cdot \sin \alpha
$$

The maximal torque of the tire which can be opposed to the motion has the following expression:

$$
T_{\max }=M g f_{r} \cdot R_{r}
$$

We obtain finally the total resistive torque:

$$
T_{v}=T_{\text {slope }}+T_{\text {tire }}+T_{\text {aero }}
$$

\subsubsection{Gear}

The speed gear ensures the transmission of the motor torque to the driving wheels. The gear is modelled by the gear ratio, the transmission efficiency and its inertia.

The mechanical equation is given by:

$$
J_{e} \frac{d w_{m}}{d t}+f w_{m}=p\left(T_{e m}-T_{r}\right)
$$

with:

$$
\begin{aligned}
& T_{r}=\frac{1}{\eta N_{r e d}} T_{v} \\
& J_{e}=J+\frac{J_{v}}{\eta N_{r e d}^{2}}
\end{aligned}
$$

The modelling of the traction system allows the implementation of some controls such as the vector control and the speed control in order to ensure the globally system stability.

\section{Vector control}

The main objective of the vector control of induction motors is, to control independently the flux and he torque as DC machines, this is done by using a $\mathrm{d}-\mathrm{q}$ rotating reference frame synchronously with the rotor flux space vector $[6,7]$. In ideally field-oriented control, the rotor flux linkage axis is forced to align with the d-axes, and it follows that $[7,10,13,14]$ :

$$
\phi_{r q}=\frac{d \phi_{r q}}{d t}=0
$$

$$
\phi_{r d}=\phi_{r}=\text { constan } t
$$

Applying the result of (13) and (14), namely the indirect field-oriented control, the torque equation become analogous to the DC machine and can be described as follows:

$$
T_{e}=\frac{3}{2} \frac{p \cdot L_{m}}{L_{r}} \cdot \phi_{r} \cdot i_{q s}
$$

And the slip frequency can be given as follow:

$$
\omega_{s l}=\frac{1}{\tau_{r}} \frac{i_{q s}^{*}}{i_{d s}^{*}}
$$

Consequently, the dynamic equations (1) yield:

$$
\begin{aligned}
\frac{d i_{d s}}{d t} & =-\left(\frac{R_{s}}{\sigma L_{s}}+\frac{1-\sigma}{\sigma \tau_{r}}\right) i_{d s}+\omega_{e} i_{q s}+\frac{L_{m}}{\sigma L_{s} L_{r} \tau_{r}} \varphi_{r d}+\frac{1}{\sigma L_{s}} V_{d s} \\
\frac{d i_{q s}}{d t} & =-\left(\frac{R_{s}}{\sigma L_{s}}+\frac{1-\sigma}{\sigma \tau_{r}}\right) i_{q s}-\omega_{e} i_{d s}+\frac{L_{m}}{\sigma L_{s} L_{r} \tau_{r}} \varphi_{r d}+\frac{1}{\sigma L_{s}} V_{d s} \\
\frac{d \phi_{r}}{d t} & =\frac{L_{m}}{\tau_{r}} i_{d s}-\frac{1}{\tau_{r}} \phi_{r d} \\
\frac{d \omega_{r}}{d t} & =\frac{3}{2} \frac{P^{2} L_{m}}{J L_{r}} i_{q s} \phi_{r d}-\frac{f_{c}}{J} \omega_{r}-\frac{P}{J} T_{l}
\end{aligned}
$$

The decoupling control method with compensation is to obtain the inverter output voltages such that [10]:

$$
\begin{aligned}
& V_{d s}^{*}=\left(K_{p}+K_{i} \frac{1}{s}\right)\left(i_{d s}^{*}-i_{d s}\right)-\omega_{e} \sigma L_{s} i_{q s}^{*} \\
& V_{q s}^{*}=\left(K_{p}+K_{i} \frac{1}{s}\right)\left(i_{q s}^{*}-i_{q s}\right)+\omega_{e} \sigma_{s} i_{d s}^{*}+\omega_{r} \frac{L_{m}}{L_{r}} \phi_{r d}
\end{aligned}
$$

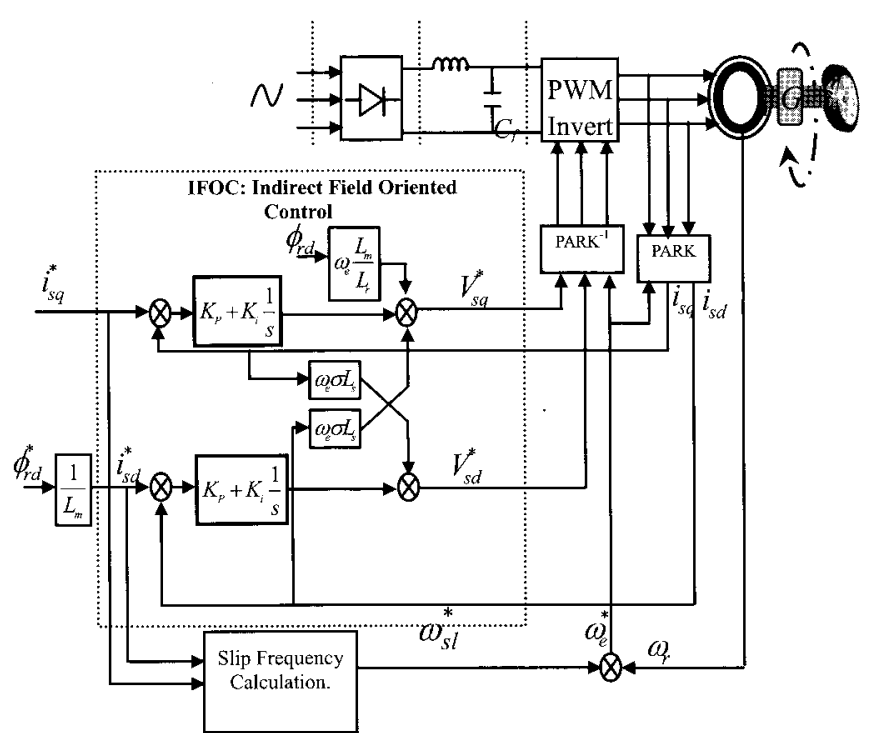

Fig. 3. Block diagram of IFOC for an EV induction motor 
According to the above analysis, the indirect fieldoriented control (IFOC) $[7,10,13,14]$ of induction motor with current-regulated with PWM inverter control system can reasonably presented by the block diagram shown in the Figure 3. In this step we use the classical regulator for IFOC tuning control parameter.

\section{Sliding mode control}

Sliding modes is phenomenon may appear in a dynamic system governed by ordinary differential equations with discontinuous right-hand sides. It may happen that the control as a function of the system state switches at high frequency, this motion is called sliding mode. It may be enforced in the simplest tracking relay system with the state variable $x(t)[4,7,10,11,14]$ :

$$
\frac{\partial x}{\partial t}=f(x)+u
$$

With the bounded function $f(x)$

$|f(x)|<f_{0} ; f_{0}$ is constant and the control as a relay function of the tracking error $e=r(t)-\frac{\partial x}{\partial t} ; r(t)$ is the reference input and $u$ is given by:

$$
u=\left\{\begin{array}{lll}
+u_{0} & \text {;if } & e>0 \\
-u_{0} & \text {;if } & e<0
\end{array}\right.
$$

Or: $u=u_{0} \operatorname{sign}(e) \quad ; \quad u$ is constant.

Figure 4 shows the relay control scheme:

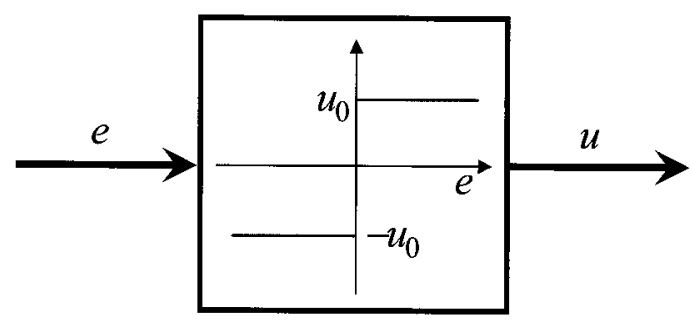

Fig. 4. relay control

The values of $e$ and $\frac{\partial e}{\partial t}=\dot{e}=\dot{r}-f(x)-u_{0} \operatorname{sign}(e)$

According to Lyapunov stability criteria the system's stable if it does verify the following condition: $e . e<0$

By means that we have the different signs if $u_{0}>f_{0}+|\dot{r}|$.

And finally $\mathbf{u}_{0}$ must be positive constant.

\subsection{Design of sliding mode speed and current control-} ler

The speed error is de fined by $[4,10,11,14,16]$ :

$$
e=w_{r e f}-w
$$

The derivative of the sliding surface can be given as:

$$
\dot{s}(\omega)=\dot{\omega}_{r}^{*}-\dot{\omega}_{r}
$$

From the equation (24) and (2), we can obtain:

$$
\dot{s}\left(\omega_{m}\right)=\dot{\omega}_{m}^{*}-\left(\frac{3}{2} \frac{P^{2} L_{m} \phi_{d r}^{*}}{J L_{r}}, i_{q s}-\frac{f_{c}}{J} \dot{\omega}_{m}-\frac{P}{J} T_{l}\right)
$$

The current control is given by:

$$
i_{q s}=i_{q s}^{e q u}+i_{q s}^{n}
$$

The discontinuous control action can be given as:

$$
i_{q s}^{n}=k_{i q s} \cdot \operatorname{Sign}\left(s(\omega) / \phi_{\omega}\right)
$$

$k_{i q s}:$ Positive constant.

The current control is defined by:

$$
i_{q s}^{e q u}=\frac{2}{3} \frac{J L_{r}}{P^{2} L_{m} \phi_{d r}^{*}}\left(\dot{\omega}_{m}^{*}+\frac{f_{c}}{J} \omega_{m}+\frac{P}{J} T_{l}\right)
$$

For the IFOC tuning parameters we need two surfaces $S_{1}$ and $S_{2}$ the first for the $i_{d s}$ regulator and the second for $i_{q s}$ regulator respectively where:

$$
\begin{aligned}
& s_{1}=i_{d s}^{*}-i_{d s} \\
& s_{2}=i_{q s}^{*}-i_{q s}
\end{aligned}
$$

The derivate of $S_{1}$ can be given as:

$$
\dot{s}_{1}=\dot{i}_{d s}^{*}-\dot{i}_{d s}
$$

from equation (2) and (30) we can obtain :

$$
\dot{s}_{1}=\dot{i}_{d s}-\left[-\left(\frac{R_{s}}{\alpha_{s}}+\frac{1-\sigma}{\sigma \tau_{r}}\right) \dot{i}_{d s}+\omega_{e} i_{q s}+\frac{L_{m}}{d_{s} L_{r} \tau_{r}} \phi_{r d}+\frac{1}{\alpha_{s}} V_{d s}\right]
$$

The virtual voltage controller $V_{d s}$ is given by: 
$V_{d s}=V_{d s}^{e q u}+V_{d s}^{n}$

The voltage discontinuous control $V_{d s}^{n}$ is defined as:

$$
V_{d s}^{n}=k_{1} \cdot \operatorname{Sign}\left(s_{1} / \phi_{1}\right)
$$

According to Lyapunov stability criteria $[10,11]$ our speed loop(figure.8) system's sable if: $s_{1} s_{1}<0$ by means that $K_{l}$ is positive constant.

The equivalent control $V_{d s}^{e q u}$ is given as:

$$
V_{d s}^{e q u}=\sigma \cdot L_{s}\left(\dot{i}_{d s}^{*}+\frac{1}{\sigma \cdot L_{s}}\left(R_{S}+R_{r} \cdot\left(\frac{L_{m}}{L_{r}}\right) 2\right) i_{d s}-w_{s} \cdot i_{q s}-\frac{L_{m} \cdot R_{r}}{\sigma \cdot L_{s} L_{r}^{2}} \phi_{r}^{*}\right)
$$

The derivate of $S_{2}$ can be given as:

$$
\dot{s}_{2}=\dot{i}_{q s}^{*}-\dot{i}_{q s}
$$

From equation (2) and (31) we can obtain:

$$
\dot{s}_{2}=\dot{i}_{q s}-\left[-\left(\frac{R_{s}}{\alpha_{s}}+\frac{1-\sigma}{\sigma \tau_{r}}\right) i_{q s}-\omega_{e} i_{d s}+\frac{L_{m}}{\alpha_{s} L_{r} \tau_{r}} \phi_{r d}+\frac{1}{\alpha_{s}} V_{q s}\right]
$$

The voltage controller $V_{q s}$ is given by:

$$
V_{q s}=V_{q s}^{e q u}+V_{q s}^{n}
$$

The $V_{q s}^{e q u}$ equivalent control actions defined as:

$$
V_{q s}^{e q u}=\sigma L_{s} \cdot\left[i_{q s}^{*}+\omega_{s} i_{d s} \frac{1}{\sigma L_{s}}\left(R_{s}+R_{r}\left(\frac{L_{m}}{L_{r}}\right)^{2}\right) i_{q s}+\frac{L_{m}}{L_{s} L_{r}} \phi_{r}^{*} \omega_{m}\right]
$$

The voltage discontinuous control $V_{d s}^{n}$ is defined as:

$$
V_{q s}^{n}=k_{2} \cdot \operatorname{Sign}\left(s_{2} / \phi_{2}\right)
$$

For the same reason condition of $K_{I}$ :

$K_{2}$ is positives constant.

\section{Fuzzy-sliding mode control (FSMC)}

The disadvantage of sliding mode controllers is that the discontinuous control signal produces chattering dynamics; chatter is aggravated by small time delays in the system. In order to eliminate the chattering phenomenon, different schemes have been proposed in the literature $[10,11]$. In this section, a Fuzzy-Sliding mode controller is developed, in which a fuzzy inference mechanism is used to generate the equivalent control law parameters. The proposed fuzzysliding mode controller scheme for EV speed control is shown in Figure 5. The fuzzy logic controllers replace the inequalities given in (29) which determine the parameters of the equivalent control action. We follow the development established in $[12,14]$ and show that a particular fuzzy controller is an extension of an SMC with a boundary layer $[10,11,12]$. The proposed fuzzy controller in this paper is constructed from the following IFTHEN rules:

$\begin{array}{ll}\text { BN : Big Negative } & \text { Bigger } \\ \text { MN : Medium Negative } & \text { Big } \\ \text { ZE : Zero } & \text { Medium } \\ \text { MP : Medium Positive } & \text { Small } \\ \text { BP : Big Positive } & \text { Smaller }\end{array}$

The figure. 5 shows the Fuzzy Sliding Mode Control (FSMC) control strategy scheme for the electric traction chain.

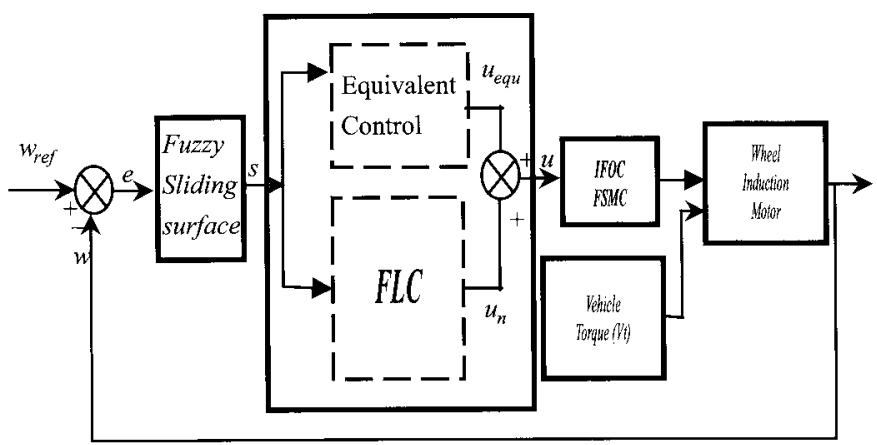

Fig. 5. The FSMC EV control strategy scheme

Since only five fuzzy subsets, BN, MN, ZE, MP and BP, are defined for $s, s_{I}$ and $s_{2}$; the fuzzy inference mechanism contains five rules for the Fuzzy Logic Controller (FLC) output.

The resulting fuzzy inference rules for the output variable $u_{n}$ of as follows:

Rule 1: IF $s, s_{1}$ and $s_{2}$ is BN THEN $u_{n}$ is Bigger

Rule 2: IF $s, s_{1}$ and $s_{2}$ is MN THEN $u_{n}$ is Big

Rule 3: IF $s, s_{1}$ and $s_{2}$ is ZE THEN $u_{n}$ is Medium

Rule 4: IF $s, s_{1}$ and $s_{2}$ is MP THEN $u_{n}$ is Small

Rule 5: IF $s, s_{1}$ and $s_{2}$ is BP THEN $u_{n}$ is Smaller

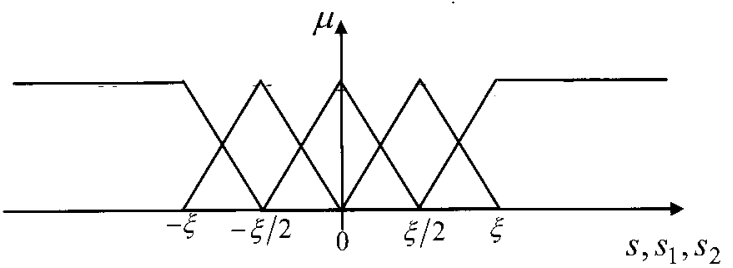

Fig. 6. The inputs $s, s_{1}$ and $s_{2}$ membership functions of the Discontinuous control 


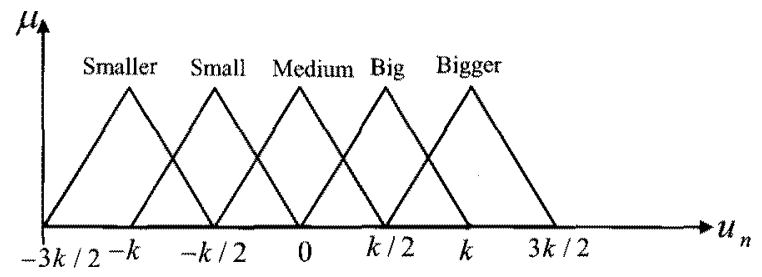

Fig. 7. The output membership function of the discontinuous control

In order to control the speed and IFOC currents of the induction motor, the three discontinuous control actions are replaced by fuzzy logic controllers as it shown in figure 8 .

The membership functions of input and output fuzzy sets are depicted in figures 6 and 7. In this study, the triangular membership functions and center average deffuzzification method are adopted, as they are computationally simple, intuitively plausible, and most frequently used in the opening literatures.

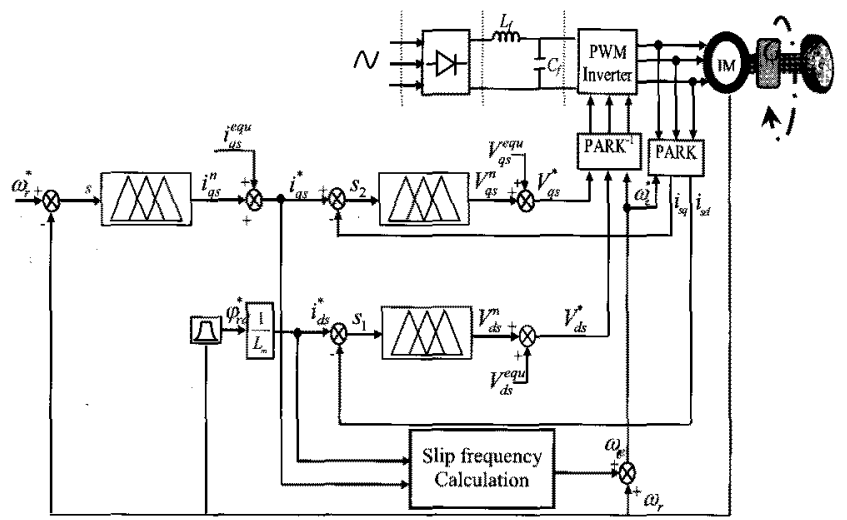

Fig. 8. The block diagram of proposed fuzzy-sliding mode speed and currents EV Wheel control

\section{Structure of the studied system}

The general scheme of the driving wheels control is represented by figure 11. It's an electric vehicle which the back driving wheels are controlled independently by two IM.

The reference blocks must provide the speed references of each motor taking into consideration information from the different sensors.

\subsection{Speed references computation}

It is possible to determine the speed references according to the requirements of the driver. When the vehicle arrives at the beginning of a curve, the driver applies a curve angle on each driving wheels $[4,5,15,17,18]$. The electronic differential acts immediately on the two motors reducing the driving wheel speed situated inside the curve, and increases the speed of the driving wheel situated outside the curve. The driving wheels angular speeds are:

$$
\begin{aligned}
& w_{r R}=\frac{V_{h}}{R_{r}}+k_{b} \cdot \Delta w \\
& w_{r L}=\frac{V_{h}}{R_{r}}-k_{b} \cdot \Delta w
\end{aligned}
$$

Where $V_{h}$ is the tangential velocity of the vehicle and

$k_{b}=+1$ corresponding to a choice of the direction of the wheel, $(-1)$ for the right turn, and $(+1)$ for the left turn. The driving wheels speed variation is imposed by the trajectory desired by the driver and it's given by:

$$
\Delta w=\frac{d_{w}}{2} \frac{\sin (\delta+\beta)}{l_{w} \cdot \cos \delta} \cdot \frac{V_{h}}{R_{r}}
$$

The relation between $\alpha$ which is the curve angle given by the driver wheel and $\delta$ of the real curve angle of the wheels is given by:

$$
\delta=\frac{\alpha}{k_{d}}
$$

The proposed propulsion system structure is similar to that of multi-converters multi-machines system [4], it is defined as a system composed by several electric drives mechanically coupled. The figure 9 represents the electric vehicle (EV) driving wheels system, where MR and ML represent the right driving motor and left driving motor respectively.

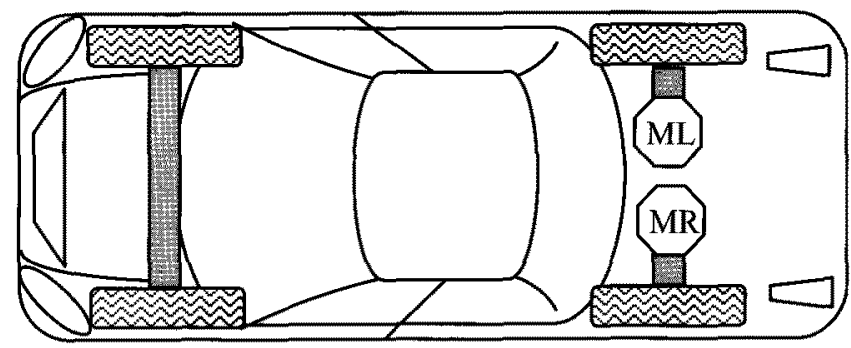

Fig. 9. The driving wheels for the electric vehicle

The figure 10 shows the vehicle geometry of the studied system.

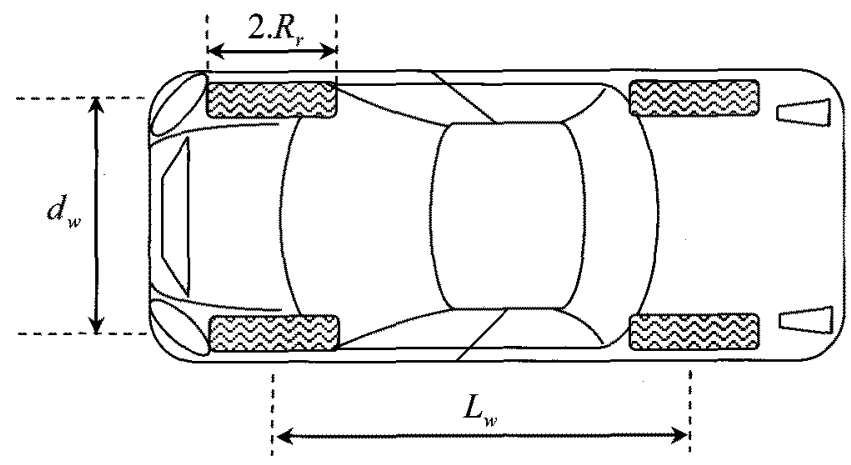

Fig. 10. The vehicle geometry 
where $k_{d}$ is the gear ratio. A proportionality coefficient between $\delta$ and $\beta$ which is the vehicle slip angle is defined by:

$$
\beta=k . \delta
$$

The speeds references of the two motors are:

$$
\begin{aligned}
& w_{m R}^{*}=N_{\text {red }} \cdot w_{r R} \\
& w_{m L}^{*}=N_{\text {red }} \cdot w_{r L}
\end{aligned}
$$

\section{Simulation results}

In order to characterize the driving wheel system behavior, simulations were carried using the model of figure 11. They show vehicle speed variation for PI controllers and the Fuzzy-Sliding mode controller.

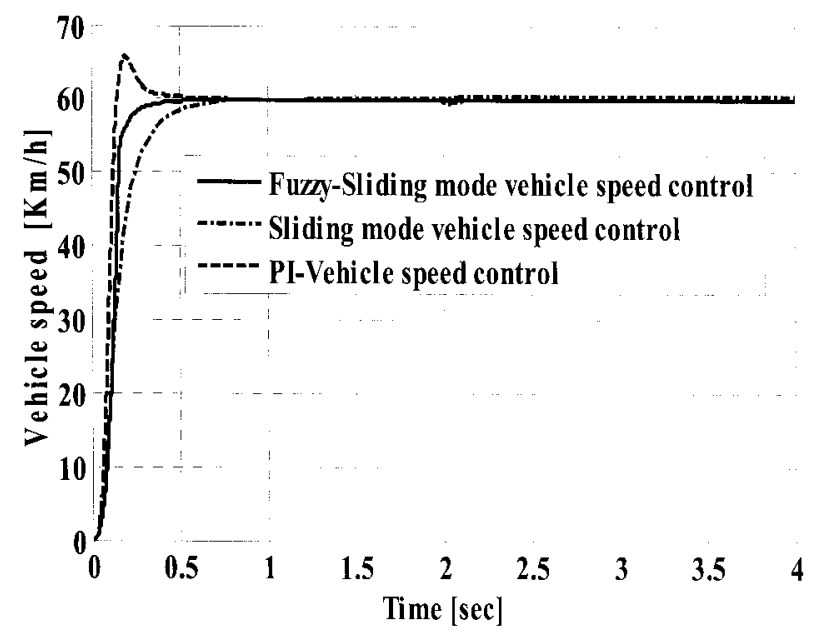

Fig. 12. Vehicle speed for two controller cases

In order to simplify the control algorithm and improve the control loop robustness, instead of using classical con- trol, we use the sliding mode control $[4,11]$. The advantage of this control is its robustness, its capacity to maintain ideal trajectories for two wheels control independently and ensure good disturbances rejections with no overshoot and stability of vehicle perfected ensured with the speed variation and less error speed.

To compare the effect of disturbances on the vehicle speed in the cases of three types of control, figure 12 shows the system response in two cases (sliding mode, robust hybrid and classical control).

We can summaries the vehicle speed results in the following tables:

Table 1. Performances of the PI \& SMC and FSMC controllers in the speed loop response

\begin{tabular}{c|c|c|c|c}
\hline Results & $\begin{array}{c}\text { Rising } \\
\text { time } \\
{[\mathrm{Sec}]}\end{array}$ & $\begin{array}{c}\text { Overtaking } \\
{[\%]}\end{array}$ & $\begin{array}{c}\text { Steady } \\
\text { state } \\
\text { error [\%] }\end{array}$ & $\begin{array}{c}\text { Disturbance } \\
\text { application time } \\
\text { (slope torque) }\end{array}$ \\
\hline PI & 0.1564 & 11.6666 & 0 & At 2 Sec \\
\hline SMC & 0.7681 & 0 & $2.7 \times 10^{-3}$ & At 2 Sec \\
\hline FSMC & 0.6008 & 0 & 0 & At 2 Sec \\
\hline
\end{tabular}

From the figure 12 and the table we can say that: the effect of the disturbance is neglected in the case of the sliding and the Fuzzy-sliding mode controllers. It appears clearly that the classical control with PI controller is easy to apply. However the control with both of sliding and the Fuzzy-sliding mode controllers offers better performances in both of the overshoot control and the tracking error.

In addition to these dynamic performances, it respects the imposed constraints by the driving system such as the robustness of parameter variations.

\subsection{Case of straight way}

- Flat road with $10 \%$ slope at $60 \mathrm{~km} / \mathrm{h}$ speed.

In this test, the system is submitted to the same speed step. The driving wheels speeds stay always the same and the road slope does not affect the control of the wheel and

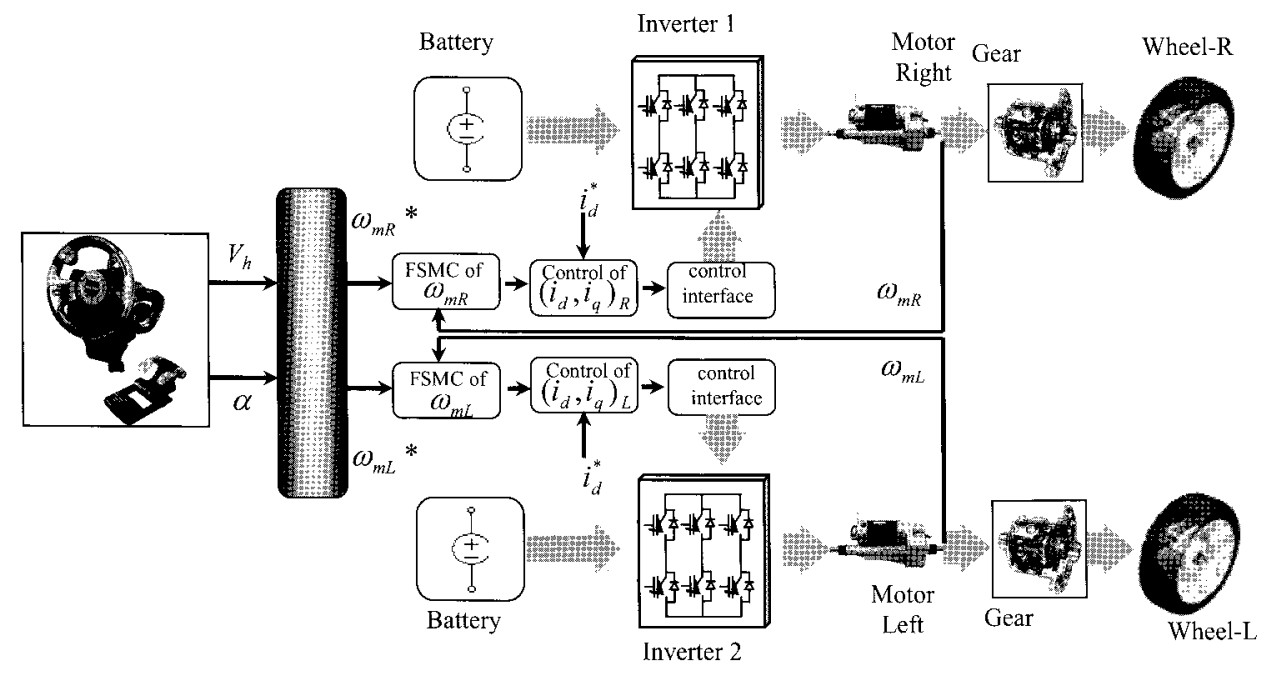

Fig. 11. The driving wheels control system 
the Fuzzy-sliding mode control act immediately on the speed loop's(figure.8;figure.11) and rejects the disturbance and give's more and more efficiency to the electronic differential output references. We can say the slope sensitize the motorization to develop efforts in order to satisfy the electric traction chain demand.

The system behaviour of theses speeds is illustrated by figures 13.1; figures 13.3 describe the electromagnetic Torque variations. It seams ha the two motors develop the same efforts in order to passe the slope .The resistant torques is shown in figures 13.2.

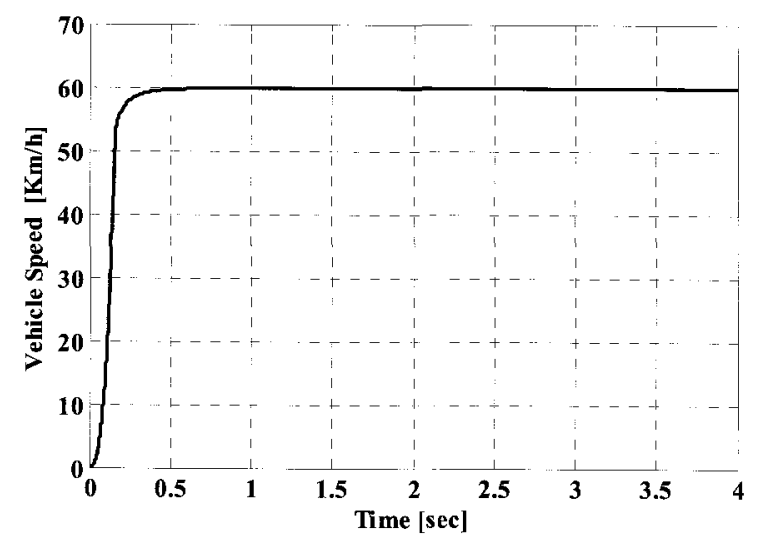

Fig. 13. 1 Vehicle wheel speed

Table 2. Performances of the PI \& SMC controllers in vehicle speed loop

\begin{tabular}{c|c|r|r|c|c|c|c}
\hline Results & $\Delta w$ & $V_{\text {refL }}^{*}$ & $V_{\text {refR }}^{*}$ & $\alpha$ & $V h$ & $V_{w L}$ & $V_{w R}$ \\
\hline PI & 0 & 60 & 60 & 0 & 60 & 59.87 & 59.87 \\
\hline FSMC & 0 & 60 & 60 & 0 & 60 & 60 & 60 \\
\hline
\end{tabular}

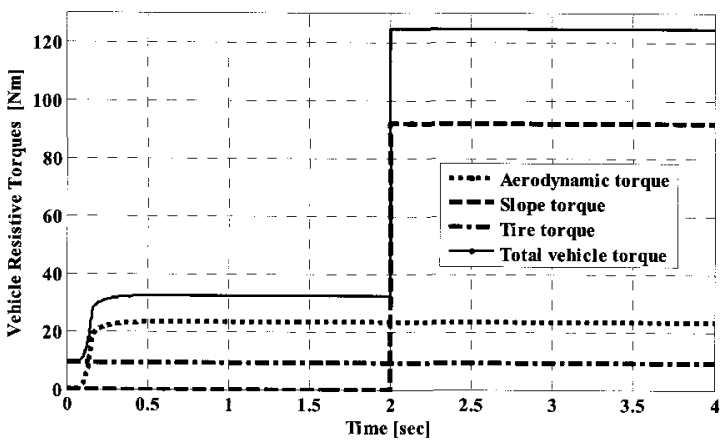

Fig. 13. 2 Resistive Torques

Table 3. Performances of the FSMC and PI controllers

\begin{tabular}{ccccc}
\hline Results & $\begin{array}{c}\text { Total vehicle } \\
\text { torques }\left(\mathrm{T}_{\mathrm{v}}\right)\end{array}$ & $\begin{array}{c}\text { Tire torque } \\
\text { (Ttire) }\end{array}$ & $\begin{array}{c}\text { Aerodynamique } \\
\text { torque (Taero) }\end{array}$ & $\begin{array}{c}\text { Slope } \\
\text { torque } \\
\text { (Tslope) }\end{array}$ \\
\hline $\begin{array}{c}\text { Maximum } \\
\text { value -FSMC } \\
{[\mathrm{Nm}]}\end{array}$ & 124.80 & 9.067 & 23.48 & 92.26 \\
\hline $\begin{array}{c}\text { Maximum } \\
\text { value -PI } \\
{[\mathrm{Nm}]}\end{array}$ & 195.00 & 9.067 & 93.7 & 92.26 \\
$\begin{array}{c}\text { Time applica- } \\
\text { tion } \\
{[\text { Sec] }}\end{array}$ & Permanent & Permanent & Permanent & 2 \\
\hline
\end{tabular}

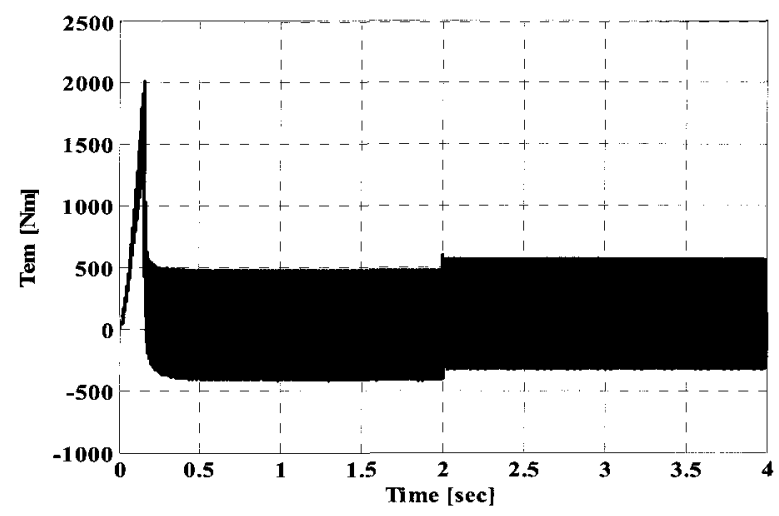

Fig. 13.3 Motor Electromagnetic Torque

\subsection{Case of curved way}

- Curved road at right side with speed of $60 \mathrm{~km} / \mathrm{h}$.

The vehicle is driving on a curved road on the right side with $60 \mathrm{~km} / \mathrm{h}$ speed. The assumption is that the two motors are not disturbed. In this case the driving wheels follow different paths, and they turn in the same direction but with different speeds.

The electronic differential acts on the two motor speeds by decreasing the speed of the driving wheel on the right side situated inside the curve, and on the other hand by increasing the wheel motor speed in the external side of the curve. The Fuzzy-sliding mode control ensure the stability of the propulsion system by maintaining the motorization error speed equal zeros and gives a good rising time and no over tracking error too The behavior of these speeds is given by figure 14.3, the variation of the vehicle torques and the electromagnetic torques are illustrated in figures 14.4 and 14.1 and figure 14. 2 .

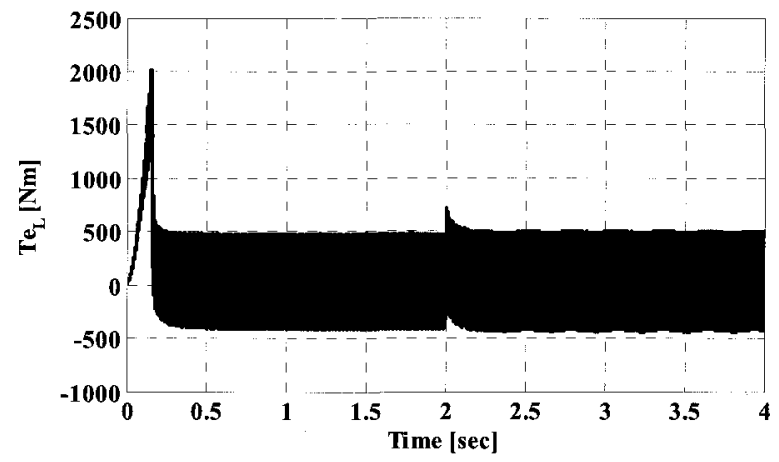

Fig. 14. 1 Left motor Electromagnetic Torque

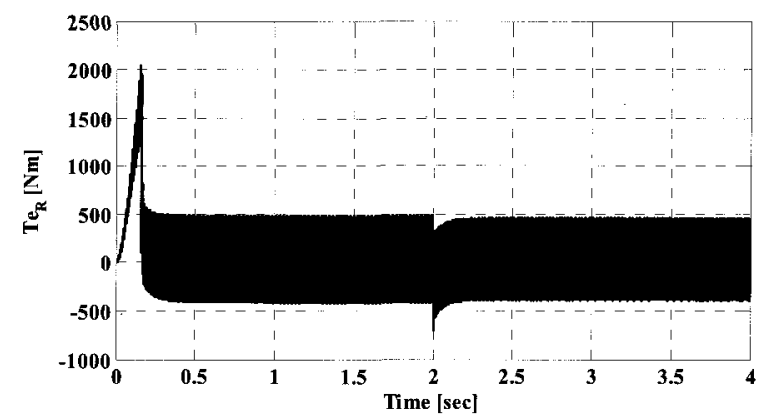

Fig. 14. 2 Right motor Electromagnetic Torque 


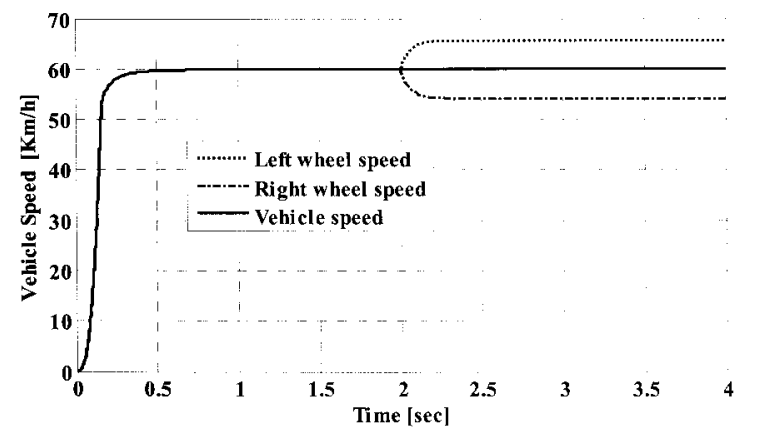

Fig. 14. 3 Vehicle speed in right turn in curved way

Table 4. Performances of the FSMC controller in the vehi-

\begin{tabular}{|c|c|c|}
\hline Results & $\mathrm{PI}$ & FSMC \\
\hline$[\mathrm{Km} / \mathrm{h}]$ & 5 & 5 \\
\hline$V_{r e f L}^{*}$ & 65.74 & 65 \\
\hline$V_{r e f R}^{*}$ & 54.26 & 55 \\
\hline Time curve [Sec] & 2 & 2 \\
\hline Curve angle $\alpha \quad\left[{ }^{\circ}\right]$ & 5.81 & 5.81 \\
\hline Vh $\quad[\mathrm{Km} / \mathrm{h}]$ & 60 & 60 \\
\hline$V_{w L}$ & 65.6 & 65 \\
\hline$V_{w R}$ & 54.15 & 55 \\
\hline
\end{tabular}

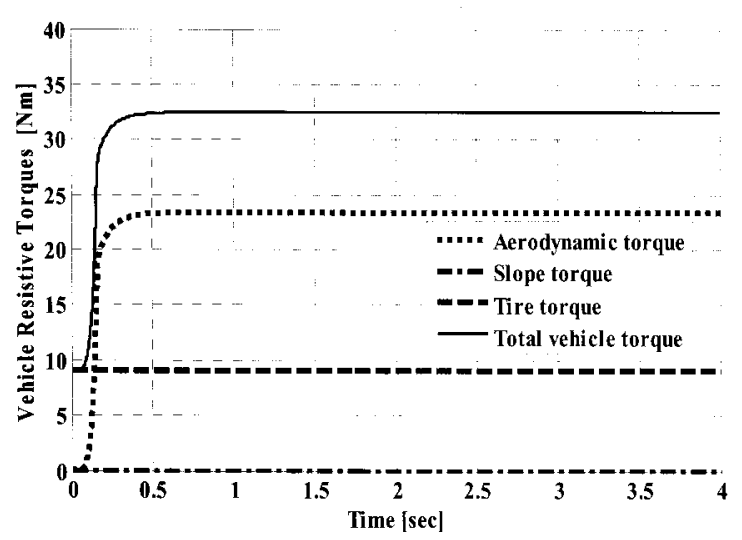

Fig. 14. 4 Resistive Torques in right turn in curved way.

Table 5. Performances of the FSMC and PI controllers on the vehicle torques response

\begin{tabular}{c|c|c|c|c}
\hline Results & $\begin{array}{c}\text { Total } \\
\text { vehicle } \\
\text { torques } \\
\left(\mathrm{T}_{v}\right)\end{array}$ & $\begin{array}{c}\text { Tire } \\
\text { torque } \\
\text { (Ttire) }\end{array}$ & $\begin{array}{c}\text { Aerodynamique } \\
\text { Torque (Taero) }\end{array}$ & $\begin{array}{c}\text { Slope } \\
\text { torque } \\
\text { (Tslope) }\end{array}$ \\
\hline $\begin{array}{c}\text { Maximum } \\
\text { value }- \\
\begin{array}{c}\text { FSMC } \\
{[\mathrm{Nm}]}\end{array}\end{array}$ & 32.65 & 9.114 & 23.44 & 0 \\
\hline $\begin{array}{c}\text { Maximum } \\
\text { value -PI } \\
{[\mathrm{Nm}]}\end{array}$ & 102.5 & 9.114 & 93.7 & 0 \\
\hline $\begin{array}{c}\text { Time } \\
\text { applica- } \\
\text { tion } \\
{[\mathrm{Sec}]}\end{array}$ & Permanent & Permanent & Permanent & $\begin{array}{c}\text { Appli- } \\
\text { cation }\end{array}$ \\
\hline
\end{tabular}

\section{Conclusion}

The research outlined in this paper has demonstrated the feasibility of an improved vehicle stability which utilises two independent back drive wheels for motion by using the fuzzy-sliding mode control. This paper proposes an 'independent machine' control structure applied to a propulsion system ensuring by the electronic differential. The results obtained by simulation show that this structure permits the realization of the robust hybrid control based on Fuzzy inference system, with good dynamic and static performances for the multi-converters/multi-machines propulsed system.

The proposed Fuzzy-Sliding mode control model improve the driving wheels speeds control with high accuracy either in flat roads or curved ones. The disturbances do not affect the performances of the driving motors and the hybrid control gives a good dynamic characteristics of the traction chain.

The major advantages of a vehicle using independent wheel control are the ability to traverse steep slopes, and the ability to have larger wheels and improved load carrying and distribution of load compared to conventional vehicles of the type.

\section{Appendix}

Table 6. Electric vehicle Parameters

\begin{tabular}{c|c|c}
\hline $\mathrm{Te}$ & Motor traction torque & $247 \mathrm{Nm}$ \\
\hline $\mathrm{J}_{\mathrm{c}}$ & Moment on inertia of the drive train & $7.07 \mathrm{Kgm}^{2}$ \\
\hline $\mathrm{R}_{\mathrm{w}}$ & Wheel radius & $0.36 \mathrm{~m}$ \\
\hline $\mathrm{a}$ & Total gear ratio & 10.0 \\
\hline$\eta$ & Total transmission efficiency & $93 \%$ \\
\hline $\mathrm{M}$ & Vehicle mass & $3904 \mathrm{Kg}$ \\
\hline $\mathrm{f}_{\mathrm{c}}$ & Bearing friction coefficient & 0.001 \\
\hline $\mathrm{K}_{\mathrm{d}}$ & Aerodynamic coefficient & 0.46 \\
\hline $\mathrm{A}$ & Vehicle frontal area & $3.48 \mathrm{~m}$ \\
\hline $\mathrm{f}_{\mathrm{v}}$ & Vehicle friction coefficient & 0.01 \\
\hline$\alpha$ & Grade angle of the road & $\mathrm{rad}$ \\
\hline $\mathrm{L}_{\mathrm{w}}$ & Distance between two wheels and axes & $2.5 \mathrm{~m}$ \\
\hline $\mathrm{d}_{\mathrm{w}}$ & Distance between the back and the front & $1.5 \mathrm{~m}$ \\
\hline
\end{tabular}

Table 7. Induction Motors Parameters

\begin{tabular}{c|c|c}
\hline $\mathrm{R}_{\mathrm{r}}$ & Rotor winding resistance (per phase) & $0.003 \Omega$ \\
\hline $\mathrm{Rs}$ & Stator winding resistance (per phase) & $0.0044 \Omega$ \\
\hline $\mathrm{L}_{\mathrm{s}}$ & Stator leakage inductance (per pohase) & $16.1 \mu \mathrm{H}$ \\
\hline $\mathrm{L}_{\mathrm{m}}$ & Magnetizing inductance (per phase) & $482 \mu \mathrm{H}$ \\
\hline $\mathrm{L}_{\mathrm{r}}$ & Rotor leakage inductance (per phase) & $12.9 \mu \mathrm{H}$ \\
\hline $\mathrm{f}_{\mathrm{c}}$ & Friction coefficient & 0.0014 \\
\hline $\mathrm{P}$ & Number of poles & 4 \\
\hline $\mathrm{Vh}$ & Vehicle linear speed & \\
\hline
\end{tabular}


Table 8. Symbols, Designation and Units

\begin{tabular}{|c|c|c|}
\hline Symbols & Nomenclature & Units \\
\hline $\mathbf{P}$ & Pole pairs & \\
\hline $\mathrm{J}$ & Rotor inertia & $\mathrm{Kg} \cdot \mathrm{m}^{2}$ \\
\hline $\mathrm{J}_{\mathrm{e}}$ & Moment of inertia of the drive train & $\mathrm{Kg} \cdot \mathrm{m}^{2}$ \\
\hline $\mathrm{J}_{\mathrm{v}}$ & Vehicle inertia & $\mathrm{Kg} \cdot \mathrm{m}^{2}$ \\
\hline $\mathrm{T}_{\mathrm{em}}$ & Electromagnetic torque & $\mathrm{Nm}$ \\
\hline$T_{v}$ & Vehicle torque & $\mathrm{Nm}$ \\
\hline $\mathrm{T}_{\text {slope }}$ & Slope torque & $\mathrm{Nm}$ \\
\hline$T_{\text {aero }}$ & Aerodynamique torque & $\mathrm{Nm}$ \\
\hline$T_{\text {tire }}$ & Tire torque & $\mathrm{Nm}$ \\
\hline $\mathrm{T}_{\mathrm{in}}$ & Inertia vehicle torque & $\mathrm{Nm}$ \\
\hline $\mathrm{N}_{\text {red }}$ & Report of speed gear & $\%$ \\
\hline $\mathrm{G}$ & Gear box & \\
\hline$\eta$ & Transmission efficiency & $\%$ \\
\hline $\mathrm{L}_{\mathrm{w}}$ & Distance between two wheels & $\mathrm{m}$ \\
\hline$d_{w}$ & $\begin{array}{l}\text { Distance between the back and the front } \\
\text { wheel }\end{array}$ & $\mathrm{m}$ \\
\hline$\rho$ & Air density & \\
\hline $\mathrm{S}$ & Frontal vehicle surface & $\mathrm{m}^{2}$ \\
\hline $\mathrm{C}_{\mathrm{x}}$ & Aerodynamic drag coefficient & \\
\hline M & Vehicle mass & $\mathrm{Kg}$ \\
\hline $\mathrm{g}$ & Gravitational acceleration & $\mathrm{N} / \mathrm{m}$ \\
\hline$\alpha$ & Angle grade of road & $\operatorname{rad}$ \\
\hline$f_{r}$ & Wheels Rolling resistance coefficient & \\
\hline $\mathrm{U}_{\mathrm{dc}}$ & Battery voltage & Volt \\
\hline$K_{b}$ & Choice of direction coefficient & $\mathrm{Rad} / \mathrm{sec}$ \\
\hline$\Delta W$ & $\begin{array}{c}\text { Angular speed variation given by electronic } \\
\text { differential }\end{array}$ & $\mathrm{Rad} / \mathrm{sec}$ \\
\hline$W_{r R}$ & Right wheel angular speed & $\mathrm{Rad} / \mathrm{sec}$ \\
\hline$W_{r L}$ & Left wheel angular speed & $\mathrm{Rad} / \mathrm{sec}$ \\
\hline$W_{m R}^{*}$ & Right wheel angular speed of reference & $\mathrm{Rad} / \mathrm{sec}$ \\
\hline$W_{m L}^{*}$ & Left wheel angular speed of reference & $\mathrm{rad}$ \\
\hline$\delta$ & Reel angle wheel curve's & $\mathrm{rad}$ \\
\hline$\beta$ & Vehicle slip angle & $\mathrm{rad}$ \\
\hline $\mathbf{K}_{\mathrm{iqs}}$ & Stator current coefficient of law control & \\
\hline$\varphi$ & Boundry layer & \\
\hline $\mathrm{K}_{\mathrm{iw}}$ & Angular speed coefficient of law control & \\
\hline Sat & Saturation surface & \\
\hline FSMC & Fuzzy sliding mode control & \\
\hline SMC & Sliding mode control & \\
\hline IFOC & Indirect Field oriented Control & \\
\hline Slip Calc & Slip Calculation & \\
\hline FLC & Fuzzy Logic Control & \\
\hline MR & The Right Motor & \\
\hline ML & The Left Motor & \\
\hline PI & Proportional Integral & \\
\hline
\end{tabular}

\section{References}

[1] A.Poursamad, M. Montazeri.'Design of GeneticFuzzy Control Strategy for Parallel Hybrid Electric Vehicles “, Control Engineering Practice,doi:10.1016/ j.conengprac.2007.10.003.

[2] Y. Pien Yang, C.Pin Lo "Current Distribution Control of Dual Directly Driven Wheel Motor for Electric Vehicles", Control Engineering Practice, Vol n ${ }^{\circ} 16$, 2008. pp.1285-1292.

[3] Hartani.K,Bourahla.M. Miloud.Y,'Electric Vehicle Stability Improvement Based on Anti-Skid Control Using Behaviour Model Control" ,Electro motion Cluj Napoca,Vol.14,Part4,Pages209-171.

[4] A.Nasri, A.Hazzab, I.K.Bousserhane, S.Hadjeri, P.Sicard, "Two Wheel Speed Robust Sliding Mode Control For Electric Vehicle Drive ",Serbian Journal of Electrical Engineering , Vol 5, No2, November 2008 ,PP 199216.

[5] Multon, B., Hirsinger, L.: Problème de la motorisation d'un véhicule Electrique (Motorization problem of an electric vehicle), EEA "Voiture et Electricité" ("Car and Electricity") 24 et 25 Mars 1994, Cachan (France).

[6] H.Rehman, R.Dhaoudi, "A fuzzy Learning-Sliding Mode Controller for Direct Field Oriented Induction Machines", Neurocomputing, Elseiver, Vol.71, 2008, pp.2693-2701.

[7] C. -M. Lin and C. -F. Hsu, "Adaptive Fuzzy SlidingMode Control for Induction Servomotor Systems", IEEE Transactions on Energy Conversion, vol. 19, $\mathrm{n}^{\circ} 2$, June 2004, pp. 362-368

[8] Yoichi, H., Yasushi, T., and Yoshimasa, T.: Traction control of electric vehicle: Basic experimental results using the test EV "UOT Electric march". IEEE. Transactions on Industry Applications. Vol.34, No.5. September/October 1998. p. 1131-1138.

[9] A. Schell, H. Peng, D. Tran, E.Stamos," Modeling and Control Strategy development for Fuel Cell Electric Vehicle", Annual Review in control Elseiver,Vol.29,2005,pp. 159-168.

[10] A.Tahour,Hamza,Abid,A.Aissaoui," Speed Control of Switched Reluctance Motor Using fuzzy Sliding Mode", Advances in Electrical and Computer Engineering ,Vol,8.15,Number 1(29), 2008.

[11] M. Abid, Y. Ramdani and A. Meroufel, "Speed Sliding Mode Control of Sensorless Induction Machine". Journal of Electrical Engineering JEEC (Slovak), Vol. 57, No.01, pp. 47-51, (2006).

[12] C.Y.Chen, T.Hseng S. Li, Y. C.Yeh ," EP-based kinematic control and adaptive fuzzy sliding-mode dynamic control for wheeled mobile robots" , Information Sciences 179 (2009) 180-195.

[13] A. Hazzab, I. K. Bousserhane, M. Kamli and M. Rahli: "New Adaptive fuzzy PI-Sliding Mode Controller for Induction Machine Speed Control". Third IEEE International Conference on Conference on Systems, Signals \& Devices SSD'05, Tunisia, (2005). 
[14] C. M. Lin and C. -F. Hsu, "Adaptive Fuzzy SlidingMode Control for Induction Servomotor Systems", IEEE Transactions on Energy Conversion, vol. 19, $\mathrm{n}^{\circ} 2$, June 2004, pp. 362-368.

[15] B.C.Besselink," Computer Controlled Steering System for Vehicles having two independently driven wheels", Computers and Electronics in Agriculure Science direct, vol.39, 2003,pp.209-226.

[16] J. -C. Le and Y. -H. Kuo, "Decoupled fuzzy slidingmode control", IEEE Trans. on Fuzzy Systems, Vol. $6 \mathrm{~N}^{\circ} 3,1998$.

[17] Y.Pin.Yang,C.Pin.Lo,"Current Distribution Control of Dual Directly Driven Wheel Motors for Electric Vehicles",Control Engineering Practice,Vol.16,2008,pp.1285-1292.

[18] Larminie, "Electric Vehicle Technology Explained", Edited by John Wiley and John Lowry, England, 2003.

Nasri Abdelfatah was born in 1978 at Bechar-Algeria, he'sreceived the electrical engineering diploma from Bechar Center University-Algeria in 2002, and the Master degree from the University of Sciences and Technology of Oran (USTO),Algeria in 2006. Currently he is an assistant teacher at Bechar University. From 2007 right now he's preparing his Phd degree in Electric vehicle propulsion system control.

Hazzab Abdeldjabar received the state engineer degree in electrical engineering in 1995 from the University of Sciences and Technology of Oran (USTO), Algeria, the M.Sc. degree from the Electrical Engineering Institute of the USTO in 1999, and the Ph.D. degree from the Electrical Engineering Institute of the USTO in 2006 . He is currently professor of electrical engineering at University of Bechar, Bechar, Algeria.

His research interests include power electronics, electric drives control, and artificial intelligence and there applications.
Ismail Khalil Bousserhane received the B.Sc. degree in electrical engineering from the Electrical Engineering Institute of the University Center of Bechar in 2000, the M.Sc. degree in electrical engineering from the University of Sciences and Technology of Oran (USTO), Algeria, in 2003 and the Ph.D. degree from the Electrical Engineering Institute of USTO in 2008. He is currently professor of electrical engineering at University of Bechar, Bechar, Algeria.

His research interests include modern control techniques and their application in electric drives control.

Hadjeri Samir received the Master degree in electrical engineering from the University of Laval, Quebec, Canada, in 1990, and Ph.D. degree from the University of Sidi BelAbbes, Algeria, in 2003. From 1991 to 2004 he was at the Faculty of Science Engineering, Department of Electrical Engineering, Sidi Bel-Abbes and Algeria, as a teaching member.

His research interests include high voltage direct current and power system analysis.

Pierre Sicard received the Master degree in industrial electronics from the University of Quebec in Trois-Rivieres, Trois-Rivieres, Canada, in 1990, and a Ph.D. degree in electrical engineering from Rensselaer Polytechnic Institute, Troy NY, USA in 1993. He is professor in electrical and computer engineering at University of Quebec in Trois-Rivieres where he is director of the Research group on industrial electronics.

His research interests include the macroscopic energetic Representation, multi-drives control and the rollingunrolling system control. 